\title{
Publicação científica como resistência feminista
}

\author{
Scientific Publication as Feminist Resistance
}

\author{
Cristina Scheibe Wolff' (iD 0000-0002-7315-1112 \\ Luzinete Simões Minella' (iD 0000-0001-7953-7385 \\ Mara Coelho de Souza Lago' (iD 0000-0001-5111-8699 \\ Tânia Regina Oliveira Ramos' (iD) 0000-0002-2477-0419
}

'Universidade Federal de Santa Catarina, Florianópolis, SC, Brasil. 88040-900

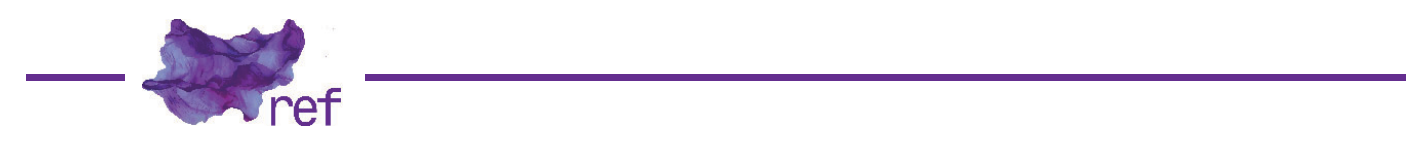

No dia 14 de junho de 2021, foi divulgado, no Jornal da Ciência, órgão informativo da Sociedade Brasileira pelo Progresso da Ciência (SBPC), um manifesto assinado pelas principais associações científicas do Brasil, denunciando a situação precária dos periódicos científicos brasileiros, como consequência da dramática redução de recursos das agências financiadoras, especialmente CAPES e CNPq, para os periódicos (SBPC, 2021). Esse manifesto seguiu-se ao anúncio de fechamento de duas importantes revistas científicas brasileiras, a Revista Sala Preta e a Revista Estudos de Literatura Brasileira Contemporânea, que funcionavam há mais de 20 anos e eram avaliadas como das mais relevantes na área de Ciências Humanas (Leandro ROCHA, 2021).

Essas notícias demonstram mais uma perda que temos na conjuntura que estamos vivendo no Brasil. Os recursos destinados à ciência, às universidades, e mesmo à educação em geral, têm sido cada vez mais reduzidos e direcionados para determinadas instituições e áreas do conhecimento, penalizando de maneira muito impactante as Ciências Humanas. Nossa revista também tem sofrido com essa redução. Apesar de atender a todos os critérios avaliativos definidos pelo sistema Qualis CAPES, pela SciELO e outros indexadores, a Revista Estudos Feministas não recebe recursos da CAPES e CNPq desde 2018. Em 2019, no último edital do CNPq para apoiar periódicos científicos, apesar de ter um score de 9,8 em 10,0, nosso projeto já não foi aprovado, em função da radical redução dos recursos desse edital (cerca apenas de 1 milhão de reais, quando o edital anterior ofereceu 4 milhões), pois foram direcionados para outras áreas do conhecimento.

O governo atual do Brasil está fazendo o que prometeu. Prometeu o "Estado Mínimo", que deixa a educação e a saúde à mercê do mercado, e para o qual a ciência não tem "serventia", especialmente as ciências humanas. Prometeu lutar contra a ideologia de gênero, e está tentando nos calar. Prometeu diminuir o serviço público, e está matando à míngua uma estrutura que foi construída por muitas décadas, que oferecia ao menos alguma saúde e educação ao povo, além de outros serviços. Essas promessas e estas ações vão contra a Constituição e precisam ser combatidas.

É interessante ver como o feminismo tem sido anunciado como um dos inimigos que deve ser enfrentado por esse movimento reacionário que se apoderou do Estado brasileiro e também de muitas pessoas e instituições, por meio do intensivo uso das mídias digitais, entre outros meios de comunicação e outras estratégias. Esse não é um movimento que acontece somente no Brasil. Como explicam Sonia Corrêa (2018), Richard Miskolci e Maximiliano Campana (2017), é possível traçar uma genealogia da "cruzada antigênero", que remonta aos esforços empreendidos pelo Vaticano em combater convenções das Nações Unidas que utilizavam esse termo, já nos anos 90. Essa conjuntura se associa ao combate ao casamento entre pessoas do mesmo "sexo" e a todas as reivindicações de maior igualdade e autonomia para as mulheres. Trata-se do que tem sido chamado de um backlash que atinge - em maior ou menor grau - países de todo o mundo, e em especial os da América Latina. 
Esse backlash não afeta apenas o feminismo, mas, como explicam Flávia Biroli e Mariana Caminotti (2020), são movimentos políticos conservadores e reacionários que mobilizam a "questão do gênero" como instrumento político. Nessa concepção, o feminismo se articula com o comunismo e também com aquilo que denominam "homossexualismo", num mesmo conjunto que deve ser repudiado. Esses movimentos também se colocam contra a ciência, invocando a religião para a explicação do mundo e da ordem social, o que inclui a ordem de gênero.

Ou seja, o que vemos acontecendo com as revistas científicas brasileiras não é obra do acaso ou da crise econômica, ou mesmo de negligência. É uma política, propositada, e vinculada a uma concepção que pretende deslegitimar a ciência e a universidade, e de quebra, o feminismo e os estudos de gênero.

Assim, continuar publicando a Revista Estudos Feministas torna-se um ato de resistência e de rebeldia. Com intenso trabalho voluntário das editoras e pareceristas, com a colaboração da Universidade Federal de Santa Catarina, particularmente dos Programas de Pós-Graduação Interdisciplinar em Ciências Humanas, História, Psicologia e Literatura e de toda a equipe do Instituto de Estudos de Gênero, estamos, a duras penas, publicando mais este número. Editar a revista com conteúdo científico, com debates no campo dos estudos de gênero, feministas e de sexualidades, tornou-se algo que vai muito além de nosso trabalho acadêmico, mas que tem um forte sentido político no contexto em que estamos vivendo.

Muitas vezes já nos sentimos cansadas, desanimadas com as barreiras e problemas. Como vamos pagar as revisoras? Como pagar a editoração? Como atender a mais essa exigência da SciELO e dos outros indexadores? Como manter a divulgação? Precisamos, nesse momento, ser feministas. Para Sara Ahmed,

viver uma vida feminista não significa adotar um conjunto de ideais ou normas de conduta, embora possa significar inquirir questões éticas sobre como viver em um mundo injusto e desigual (em um mundo não feminista e antifeminista); como criar relações com outras que sejam mais igualitárias; como encontrar formas de apoiar aquelas que não têm apoio ou que são menos apoiadas pelos sistemas sociais; como continuar seguindo contra histórias que se tornaram concreto, histórias que se tornaram sólidas como paredes (2017, p. 1, tradução livre).

Temos que continuar a enfrentar as paredes que se levantam contra nossas palavras, afinal, as palavras podem atravessar as paredes. Nesse contexto difícil, entendemos que, por meio das relações e dos apoios feministas e da colaboração de todas, é que podemos continuar esse trabalho de resistência.

É justamente sobre a questão editorial que trata o primeiro artigo deste número: "Apuntes para pensar el campo editorial en clave feminista. El caso argentino contemporâneo", que analisa trajetórias de mulheres editoras no cenário editorial argentino, contribuindo tanto para a história da edição, quanto para as questões que envolvem o trabalho e atuação das mulheres, pela perspectiva dos estudos de gênero e feministas.

Outros temas são também abordados neste número da Revista. O artigo intitulado "Disciplina y violencia contra las mujeres en la prensa del siglo XIX. Divergencia comparativa entre México y España" elabora uma análise comparativa das representações sobre as mulheres na imprensa desses dois países durante o século XIX, explorando as notícias sobre crimes bem como seus pontos de vista a respeito do cotidiano. As peculiaridades do uso das mídias digitais por uma artista dissidente são analisadas no artigo "Linn da Quebrada e os engajamentos performativos com as mídias digitais: uma análise sociológica de uma trajetória artística dissidente de gênero". A etnografia digital realizada destaca as problematizações das normas de gênero e sexualidade em suas relações com questões de raça e classe, a partir da observação das performances da artista em suas produções audiovisuais no YouTube.

O artigo "A Mulher Heroína em combate ao patriarcado em Moçambique" traz um histórico da atuação de artistas rappers moçambicanas, tendo como foco a análise da música Mulher Heroína, da rapper feminista Iveth Mafundza, artista com importante trabalho na denúncia das desigualdades de gênero, representando a expressão do rap feminista em seu país.

Nos cinco artigos seguintes, os nomes próprios e os femininos plurais permitem que as mulheres se sintam representadas ou questionadas pela linguagem em suas importâncias históricas no espaço e no tempo. No texto intitulado "Celia La Palma de Emery: experiencia en la cooperación salesiana. Argentina, 1906-1929", a autora apresenta o itinerário da militante argentina nas primeiras décadas do século XX, destacando especialmente a importância histórica da atuação de mulheres na esfera da sociabilidade associativa.

O artigo "Ignez é morta: reflexões acerca da clausura para as irmãs clarissas (séculos XIII ao XVIII)", cujas autoras realizam pesquisa em documentos, procura preencher uma lacuna na história das religiões, mais especificamente na Igreja Católica no século XIII: a instituição da clausura feminina. Ao pensar a linguagem neste universo dos estudos de gênero, as autoras de "A legendagem do discurso da sexualidade em The Magdalene Sisters" (no Brasil estreado sob o título Em Nome de Deus) nos apresentam uma leitura fílmica para assinalar que os procedimentos 
de tradução - adotados no processo de legendagem do idioma inglês para o português brasileiro - refletem a desigualdade de gênero e a misoginia com base teológica que permeia a narrativa.

Ao percorrer o espaço contemporâneo da história das mulheres na América Latina, dois artigos se aproximam, um pela visibilidade, o outro pelo apagamento: "Estereotipos de género sobre Camila Vallejo en un diario sensacionalista chileno: el caso de Las Últimas Noticias" ressalta a importância do movimento estudantil chileno durante os anos 2010 e 2011 e analisa a importância da voz, do corpo, da presença e dos discursos da líder Camila Vallejo, presidenta da Federación de Estudiantes de la Universidad de Chile. Por outro lado, "Un lugar en el campo literario: Marvel Moreno como la 'escritora reservada"' aborda uma das questões centrais para a história da literatura literária: a invisibilidade de escritoras no campo literário ou na formação do cânone, questão relevante para os estudos de autoria feminina e a visibilidade autoral.

O artigo "Do segredo à fofoca: mulheres que reescrevem a história na poesia brasileira contemporânea" propõe uma rasura à noção de segredo de Derrida utilizando a "fofoca", conforme teorizada por Silvia Federici, como uma reescrita da história hegemônica, colonial e patriarcal. Trazendo ao texto poemas de diferentes poetas brasileiras, a autora busca outra narrativa, no intuito de afirmar um outro olhar, uma literatura feminina que se alia ao lado das/ os que correm risco.

Relatos de cientistas bem-sucedidas nas áreas de ciência e tecnologia são contemplados no artigo seguinte, "Mulheres de sucesso no campo científico: uma análise de redes sociais". A pesquisa analisou reportagens por elas divulgadas na rede social Facebook, nas quais se percebe as lutas individuais que travaram no enfrentamento dos obstáculos encontrados ao longo das tentativas de consolidação de suas carreiras, em virtude da falta de políticas de apoio por parte do Estado.

No texto seguinte, "Cultura da Computação para além da normatividade: participações e produções", são analisadas a exclusão e a invisibilização de figuras historicamente importantes, por meio da realização de oficinas participativas que promoveram debates sobre as mudanças culturais, as práticas e os princípios da área, incluindo as questões de gênero e diversidade.

A complexidade da situação das mulheres cujos filhos estão no cárcere é explorada no artigo "'Maternidade guerreira': responsabilização, cuidado e culpa das mães de jovens encarcerados". Na pesquisa etnográfica realizada, são focalizadas as especificidades dos sentimentos das mães que cuidam dos filhos encarcerados, assumindo, de certa forma, a culpa e a responsabilização pelas suas ações. Ressalta-se a relevância da criação de redes espontâneas de cuidados envolvendo mulheres em situação semelhante, pois atenuam os estigmas e as violências que enfrentam na sua condição de visitantes.

No artigo "'Da Igreja à Luta': trajetórias políticas de mulheres agricultoras", as autoras analisam histórias de mulheres agricultoras da região Sudoeste do Paraná, uma história de mulheres de luta, que se fizeram militantes políticas em espaços diferentes, passando pela igreja, sindicato, associações, partido político e movimentos sociais. As vidas destas mulheres agricultoras que se tornaram lideranças políticas são também marcadas pelas interseccionalidades de classe, raça, gênero, situação rural e experiência histórica.

Continuando numa perspectiva histórica, o artigo "La práctica del aborto en manos de feministas en los 70" analisa os serviços de aborto clandestinos prestados por organizações feministas em algumas cidades dos Estados Unidos, Itália e França no período de 1969 a 1978. O texto aborda essas experiências a partir de suas motivações e resultados políticos, pois essa era a ideia dessas organizações, que buscavam a abertura de serviços públicos de aborto, e a práxis feminista envolvida.

Esse mesmo tipo de práxis feminista aparece também no artigo "Un aborto feminista es un aborto cuidado. Prácticas de cuidado en el socorrismo patagónico", que discute uma rede de cinquenta organizações feministas argentinas que acompanhavam a realização de abortos com medicação. Tratava-se de prática política arriscada, visando a legalização, despenalização e legitimação do aborto na Argentina. Muito importante esse artigo, para que possamos compreender a campanha vitoriosa do movimento pela descriminalização do aborto nesse país.

O ativismo feminista também é o tema do artigo "O feminismo não é entregue de bandeja: saberes e práticas de um Coletivo feminista estudantil", mas dessa vez se trata do Sul do Brasil, e de um coletivo de estudantes de ensino médio, que foi acompanhado através de pesquisa participante, análise documental e de um encontro de sistematização de experiências. As autoras chegaram a três principais "campos" abordados nas representações sociais do grupo: sororidade, corpos e sexualidades, e 'ser' mulher/'ser' feminista.

O artigo final desta primeira seção da revista, "'Confusão, indecisão e incerteza': enunciados de bissexualidade na jurisprudência", analisa decisões de Tribunais de Justiça da região sudeste do Brasil sobre a enunciação da bissexualidade em documentos jurídicos, na sua associação a formas de violência e em sua apresentação como sexualidade diferenciada. 
Utilizando análise de conteúdo, as autoras e autor se detêm na problematização dos enunciados de uma decisão jurídica tornada paradigmática sobre o tema.

Este número da REF apresenta duas entrevistas de acadêmicas voltadas para temas caros à agenda feminista, cujas discussões estão fundamentalmente imbricadas com a questão de políticas públicas interseccionadas, quais sejam, os temas de cuidados, trabalho, saúde, relações humanas que, por sua vez, envolvem projetos de sociedade mais justas e inclusivas.

A entrevista realizada com Eva Kittay, reconhecida internacionalmente pela importância de sua obra no campo da filosofia da dependência, traz um relato dos desdobramentos das reflexões e produção da entrevistada, em sua significativa contribuição para temas como a ética dos cuidados (que recai normalmente sobre mulheres). Fala do desenvolvimento de um saber filosófico sobre a questão da interdependência humana entre pessoas desiguais, sobre deficiência cognitiva, sobre responsabilização pelos vulneráveis, questão que precisa ser pensada em termos societários, de políticas públicas, numa economia de cuidados que ultrapasse as soluções individualizadoras, sem deixar de envolver a todas e todos nessa questão da interdependência que caracteriza o humano.

A entrevista com a farmacêutica feminista Clair Castilhos Coelho, pós-graduada em Saúde Pública, área em que construiu sua carreira acadêmica na Universidade Federal de Santa Catarina, relata a trajetória dessa militante com atuação importante nos movimentos locais, nacionais e internacionais de saúde feminina e feminismos. Com um destacado trabalho ativista em muitas frentes de atuação, Clair participou da criação da Casa da Mulher Catarina e da Rede Feminista de Saúde, atuando também no Conselho Nacional de Saúde. Tendo participado de política partidária, foi eleita a primeira vereadora mulher da câmara municipal de Florianópolis. Temos muito orgulho de contar com esta companheira no Instituto de Estudos de Gênero da UFSC.

A seção temática "Gêneros, tecnologias e (novas) formas de subjetivação nas práticas esportivas" atualiza discussões relevantes sobre o esporte, atividade que surgiu marcada como essencialmente masculina e teve que se abrir para incluir outros corpos, derrubando barreiras de gênero, de normatização do corpo, de orientação sexual, em processos sempre longos e penosos, como demonstram autoras e autores dos artigos que o compõem.

De acordo com o/a organizador/a, a seção procurou apresentar um amplo espectro de análises "...de possibilidades sobre as práticas esportivas em sua interface com a sociedade, evocando contribuições de várias áreas de conhecimento, dos Estudos de Gênero à Educação Física, passando pelas História e Ciências Sociais, com a pretensão de ser locus de discussão de pesquisas atuais" (Wagner CAMARGO; Helena ALTMAN, 2021). A variedade de estudos trazidos à seção temática questiona a própria estrutura do esporte, em suas perspectivas corponormativa, cisheteronormativa, capacitista e patriarcal, fundada nos binarismos de sexo e gênero.

As resenhas aqui publicadas se destacam por questões pontuais: pelo número significativo de submissões, pelas jovens autorias, na maioria feministas em formação, pela biblioteca contemporânea que aqui apresentamos, pelas referências de bons lançamentos e pelas subjetividades nos textos, onde a objetividade cede lugar a interpretações, posicionamentos críticos e diálogos com as questões de gênero e a crítica feminista. Esta sessão tem sido a prova significativa da produtividade das Ciências Humanas e dos estudos da linguagem tão desvalorizadas pela atual política governamental brasileira e se constitui em evidência da nossa resistência. Não vamos parar de publicar, tem sido a voz que ecoa em cada reunião de editorias diante das muitas avaliações e encaminhamentos. Não vamos parar de traduzir e não vamos parar de resenhar e, assim, oferecer sugestões fundamentais para a atualização de nossas abordagens, seja com o campo da independência sexual e econômica revisto pelo feminismo, como o queer e o corpo, com as mulheres precursoras na cura e na ciência dialogando com a mulher e a intelectualidade no contemporâneo tempo da pandemia, com o urgente feminismo decolonial e o vir a ser da interseccionalidade, temas dos livros resenhados neste número e que pedem a urgência do debate entre acadêmicas e ativistas.

\section{Referências}

AHMED, Sara. Living a feminist life. Durham: Duke University Press, 2017.

BIROLI, Flávia; CAMINOTTI, Mariana. "The conservative backlash against gender in Latin America". Politics \& Gender, v. 16, n. 1, 2020.

CAMARGO, Wagner Xavier de; ALTMAN, Helena. "Deslocamentos políticos e de gênero no esporte". Revista Estudos Feministas, v. 29 n. 2, e80215, 2021.

CORRÊA, Sonia. "A 'política do gênero': um comentário genealógico". Cadernos Pagu [online], n. 53, 2018. e185301. Disponível em https://doi.org/10.1590/18094449201800530001. Acesso em 17/06/2021. Epub 11 Jun 2018. ISSN 1809-4449. 
MISKOLCI, Richard; CAMPANA, Maximiliano. “'Ideologia de gênero': notas para a genealogia de um pânico moral contemporâneo". Sociedade e Estado [online], v. 32, n. 3, p. 725-748, 2017. Disponível em https://doi.org/10.1590/s0102-69922017.3203008. Acesso em 17/06/2021. ISSN 0102-6992.

ROCHA, Leandro. "ABEC Brasil lamenta encerramento das atividades de dois periódicos". Associação Brasileira de Editores Científicos - ABEC, 01/06/2021. Disponível em https://www. abecbrasil.org.br/novo/2021/06/abec-brasil-lamenta-encerramento-das-atividades-de-doisperiodicos/. Acesso em 16/06/2021.

SBPC. SOCIEDADE BRASILEIRA PARA O PROGRESSO DA CIÊNCIA. "Entidades se manifestam sobre a situação dos periódicos científicos brasileiros". Jornal da Ciência, n. 6673, 14/06/2021. Disponível em http://www.jornaldaciencia.org.br/edicoes/?url=http://icnoticias.jornaldaciencia.org.br/1 entidades-se-manifestam-sobre-a-situacao-dos-periodicos-cientificos-brasileiros/. Acesso em $16 / 06 / 2021$.

Cristina Scheibe Wolff (cristiwolff@gmail.com) é doutora em História Social pela Universidade de São Paulo (1998). Possui Graduação em História pela Universidade Federal de Santa Catarina (1988), Mestrado em História pela Pontifícia Universidade Católica de São Paulo (1991). Em 2004/2005 realizou Pós-Doutorado na Université Rennes 2, na França, e entre 2010 e 2011 , no Latin American Studies Center da University of Maryland, em College Park, Estados Unidos da América. Ocupou a Cátedra Fulbright de Estudos Brasileiros na University of Massachusetts em Amherst (set.-dez. 2017) e foi pesquisadora convidada no Laboratoire Arenes - Université Rennes 2 (jan.-jul. 2018). Atualmente, é Professora Titular do Departamento de História da Universidade Federal de Santa Catarina. É integrante do Laboratório de Estudos de Gênero e História (LEGH) e do Instituto de Estudos de Gênero da UFSC e uma das coordenadoras editoriais da Revista Estudos Feministas (2006-2009 e 201 1-atual). Foi coordenadora do Programa de Pós-Graduação em História da Universidade Federal de Santa Catarina. Atua ainda no Programa de Pós-Graduação Interdisciplinar em Ciências Humanas e no Mestrado Profissional de Ensino de História. Foi a coordenadora geral do Fazendo Gênero 11 e $13^{\circ}$ Women's Worlds Congress, realizado na UFSC em 2017. Tem experiência na área de História, com ênfase em História das Mulheres e do Gênero, atuando principalmente nos seguintes temas: gênero, memória, guerrilha, resistência às ditaduras no Cone Sul.

Luzinete Simōes Minella (simoesluzinete@gmail.com) é doutora em Sociologia pela Universidad Nacional Autónoma de Mexico (UNAM, 1989), graduada (1972) e mestre (1977) em Ciências Sociais pela UFBA. Realizou estágio de Pós-Doutorado no Núcleo de Estudos de População da Universidade Estadual de Campinas (NEPO/Unicamp, 1998). Atualmente, é Professora Adjunta IV aposentada da Universidade Federal de Santa Catarina (UFSC), atuando como Professora Voluntária no PPG Interdisciplinar em Ciências Humanas, onde coordena a área de Estudos de Gênero. Integra a equipe do Instituto de Estudos de Gênero (IEG), participando de vários dos seus projetos (eventos, publicações, cursos etc.). Publicou vários artigos em periódicos de ampla circulação, livros, trabalhos completos em anais de eventos etc. Assumiu a coordenação editorial da Revista Estudos Feministas entre 2001 e 2004 e entre 2007 e 2008, quando passou a integrar a editoria de artigos. Voltou a fazer parte desta coordenação em dezembro de 2016. É membro da Rede Iberoamericana de Ciencia, Tecnología y Género. Tem realizado pesquisas principalmente nas seguintes áreas: participação das mulheres nas ciências (na interface com a crítica feminista à ciência, aos estudos sociais da ciência e à história da ciência), gênero e saúde reprodutiva, gênero e infância, saúde mental. Orientou trabalhos de conclusão de curso e tem orientado dissertações e teses, principalmente nessas áreas.

Mara Coelho de Souza Lago (maralago07@gmail.com) é doutora em Psicologia da Educação pela Universidade Estadual de Campinas e Professora Emérita da Universidade Federal de Santa Catarina. Possui Graduação em Pedagogia pela Universidade do Estado de Santa Catarina (1967) e Mestrado em Antropologia Social pela Universidade Federal de Santa Catarina (1983). Atualmente, é Professora Titular aposentada da Universidade Federal de Santa Catarina/ UFSC, atuando como docente voluntária no Programa de Pós-Graduação em Psicologia/PPGP e no Programa de Pós-Graduação Interdisciplinar em Ciências Humanas/PPGICH. Tem experiência na área de Psicologia, com ênfase em Psicologia Social, atuando principalmente nos temas gênero, gerações, subjetividades, modos de vida, com enfoque interdisciplinar. Participa do Instituto de Estudos de Gênero (IEG/UFSC) e da coordenação editorial da Revista Estudos Feministas. 
Tânia Regina Oliveira Ramos (taniareginaoliveiraramos@gmail.com) é doutora em Literaturas de Língua Portuguesa pela Pontifícia Universidade Católica do Rio de Janeiro. Possui Graduação em Letras pela Universidade Federal de Santa Catarina, Mestrado e Doutorado em Literaturas de Língua Portuguesa pela Pontifícia Universidade Católica do Rio de Janeiro. Atualmente, é Professora Titular e coordena o núcleo Literatura e Memória da UFSC, núcleo com projetos aprovados pela FAPESC e CNPq. Faz parte da Coordenação Geral da Revista Estudos Feministas e do Conselho Editorial das revistas UniLetras, Mafuá Ciências e Letras, Literatura Hoje, Signótica e Anuário de Literatura. É professora de Literatura Brasileira e Estudos Literários nos Cursos de Graduação e Pós-Graduação em Letras e Literatura na UFSC. Atua, pesquisa e publica nas linhas de pesquisa História e Memória, escritas de si e gênero.

\section{COMO CITAR ESSE ARTIGO DE ACORDO COM AS NORMAS DA REVISTA}

WOLFF, Cristina Scheibe; MINELLA, Luzinete Simões; LAGO, Mara Coelho de Souza; RAMOS, Tânia Regina Oliveira. "Publicação científica como resistência feminista". Revista Estudos Feministas, Florianópolis, v. 29, n. 2, e82939, 2021.

\section{CONTRIBUIÇĀO DE AUTORIA}

Elaboração e redação coletiva.

\section{FINANCIAMENTO}

Não se aplica.

\section{CONSENTIMENTO DE USO DE IMAGEM}

Não se aplica.

\section{APROVAÇĀO DE COMITÊ DE ÉTICA EM PESQUISA}

Não se aplica

\section{CONFLITO DE INTERESSES}

Não se aplica.

\section{LICENÇA DE USO}

Este artigo está licenciado sob a Licença Creative Commons CC-BY 4.0 International. Com essa licença você pode compartilhar, adaptar, criar para qualquer fim, desde que atribua a autoria da obra.

\section{HISTÓRICO}

